\title{
Research on Reform of Tax-sharing System in the Background of Tax and Charges Reduction
}

\author{
Yang Le ${ }^{1}$, Yu Naifu ${ }^{2,}$ * \\ ${ }^{1}$ School of Public Finance and Tax, Central University of Finance and Economics, Beijing, China \\ ${ }^{2}$ School of Economics, Northwest Minzu University, Lanzhou, China \\ Email address: \\ 1285112286@qq.com (Yu Naifu) \\ ${ }^{*}$ Corresponding author \\ To cite this article: \\ Yang Le, Yu Naifu. Research on Reform of Tax-sharing System in the Background of Tax and Charges Reduction. International Journal of \\ Finance and Banking Research. Vol. 5, No. 6, 2019, pp. 166-173. doi: 10.11648/j.ijfbr.20190506.15
}

Received: October 29, 2019; Accepted: November 18, 2019; Published: November 22, 2019

\begin{abstract}
Since 2015, Chinese governments at all levels have been advancing high-frequency tax and charges reduction, and the frequency of charges reductions is surprising. China has continuously deepened reform of tax-sharing system, constantly expanding local government power and increasing economic vitality. In order to promote the sustained and healthy development of China's economy, we should maintain a reasonable scale of government charges, adjust the charges range of the central and local governments, and further improve China's fiscal decentralization system and government charges management mechanism. In this paper, it mainly researches two-way interactive effect between financial decentralization and public service charges. The data of 31 provinces in China from 1999 to 2017 was used to construct the simultaneous equations model for financial decentralization and public service charges, and then the empirical test was carried out for the interactive effect between the two with 3sls method. The research results show that there is a positive interaction between financial decentralization and public service charges. That is, the public service charges is decreased with the increase of the degree of financial decentralization. Local governments gain more power, lower fees and promote economic development. The degree of financial decentralization is increased with the decrease of public service charges. Lower fees mean less government intervention in the economy and the degree of decentralization increases. In addition, the effect degree of the control variables related to financial decentralization and public service charges was analyzed in this paper.
\end{abstract}

Keywords: Financial Decentralization, Public Service Charges, Two-way Interactive Effect

\section{Introduction}

As everyone knows that public service charges play an important role in China. However, the charging status is different in different levels of government, which is getting higher and higher from the central to the local [1]. Due to the poor charging system and supervision, many grassroots governments have problems of irregular and illegal charges, which greatly increase the burden on enterprises. In response to this problem, Chinese governments at all levels have vigorously promoted the reform of decreasing charges since 2015 , with an amazing amount of decreasing charges. By the end of 2018, the central government decreased the number of pricing and charging items by more than half, leaving only five items. In contrast, the local governments decreased the number of pricing and charging items by nearly half, leaving only 13 items in average. Among them, there is the largest number of administrative and institutional charging items related to enterprises, which is also the main part of decreasing charges. A total of 35 charging items were canceled. Besides, NPC (National People's Congress of the people's Republic of China) and CPPCC (Chinese People's Political Consultative Conference) determined the "tax and charges reduction" as the key task in 2018.

In a broad sense, the financial decentralization not only includes the decentralization of fiscal power from the central government to the local government, but also includes the decentralization of fiscal power from the government to the society. The decentralization of fiscal power from the central government to the local government began with the reform of tax-sharing system. Moreover, the decentralization degree of 
fiscal power from the central government to the local government has been deepened with the continuous progress of this reform. As a result, the reform of tax-sharing system liberated the productive forces and promoted the rapid development of the local economy. However, some problems in the reform of tax-sharing system have gradually emerged, mainly including the unclear division and mismatching of the governmental power and financial power [2]. After the implementation of tax-sharing system, the financial resources have been moved upward continuously and the governmental power has been decentralized continuously. With the development of economy, the public has had increasing demand for public services and the scope of government's powers has expanded, thus requiring more and more fiscal revenues. However, the relatively stable tax sources and tax revenue growth can not support the revenue required for the expansion of the governmental power [3], resulting in the huge pressure on the financial revenue and expenditure of the government. The the decentralization of fiscal power from the government to the society began with the reform of "decentralization and profit-sharing". This reform was carried out mainly for the state-owned enterprises, reducing their burdens and decreasing the government's intervention in enterprises, thus allowing them to operate independently and assume sole responsibility for its profits or losses. But the reform of "decentralization and profit-sharing" has increased the burden on government revenue while promoting the rapid development of enterprises and reducing their burden. In order to make up for the shortfall of revenue and reduce expenditure, the government delegated right of charge to the departments. The departments assumed sole responsibility for their profits or losses, thus causing the the phenomenon of irregular charge to aggravate gradually.

Is there an interactive relationship between public service charges and financial decentralization in the realistic background of the continuous deepening of tax and charges reduction reform and the dilemma of financial decentralization reform? What is the influence path between them? The answers to these questions are of important theoretical and practical significance for us to implement the reform of tax and charges reduction and financial decentralization reform.

One-way correlation between financial decentralization and public service charges is mainly analyzed in the current literature. Firstly, it analyzes the influence of the degree of financial decentralization on public service charges. The degree of financial decentralization is divided into the degree of financial revenue decentralization and the degree of financial expenditure decentralization. The public service charges will be less depended on when the degree of financial revenue decentralization increases [4], while the the proportion of public service charges will be increased when the degree of financial expenditure decentralization increases [5]. Under the financial decentralization system, it researches the influence of the common response of different levels of governments and the strategic interaction of the governments at the same level on public service charges [6]. Secondly, it analyzes the influence of public service charges on the degree of financial decentralization, showing that the public service charge is an important means of economic regulation [7]. The degree of decentralization will be reduced when the public service charge within the budget increases. Furthermore, there are two main problems in the current research literature. First of all, most literature have studied the influence of the degree of financial decentralization on public service charges, but few research on the influence of public service charges on the degree of financial decentralization, especially rare research on two-way interactive effect between the two. Second, the correlation between the influence factors of financial decentralization and public service charges is not considered and there is a multiple collinearity problem in the regression process, thus affecting the rationality of the research results. In this paper, it researched the current literature and sorted out the interactive effect between the two, as well as established a theoretical framework and considered the relevant factors that affect the financial decentralization and public service charges. Moreover, the panel data of provinces from 1999 to 2017 was used to establish simultaneous equations for financial decentralization and public service charges, and three-stage least squares method was used to carry out an empirical test for their two-way interactive effect.

\section{Literature Review}

\subsection{Research on the Influencing Mechanism of the Degree of Financial Decentralization on Public Service Charges}

There are two paths of influencing mechanism of financial decentralization on public service charges. First, the central government decentralizes the financial power to the local governments, which lead to increased competition among the local governments. In order to attract foreign investment, the government implements various preferential measures to reduce the number of charges. Second, the local government decentralizes the financial power to society, promotes the reform of decentralization and profit-sharing and implements market-oriented reform, so as to continuously reduced the burden on enterprises and decrease charges.

The central government increased the degree of decentralizing financial power to the local governments, resulting in a decrease in public service charges. Besides, the competition among local governments was aggravated because the central government decentralized the financial power to the local governments. On the one hand, financial decentralization allowed governments at all levels to implement different economic policies according to their own circumstances. On the other hand, the local governments performed the zero-sum game of competing to reduce charges in order to attract foreign investments and promote local economic development, thus causing the charges lower than the market efficiency level [8]. In China, the governments below the provincial level do not have independent power to 
set up, but local governments do not have the power to set up the cancellation of charges, which generally attract foreign investments by rate cutting and reducing charging links [9]. Therefore, the financial power decentralized by central government to the local governments has caused a certain reduction in the number of public service charges within the budget.

The local government increased the degree of decentralizing financial power to society, resulting in a decrease in public service charges. The decentralization of financial power by local governments to society began with the reform of decentralization and profit-making, but the drawbacks gradually emerged with the continuous advancement of this reform. Moreover, it was mainly to reform the state-owned enterprises. For private enterprises, it had a certain bureaucratic nature no matter how the state-owned enterprises are reformed, so it is difficult to achieve the market efficiency level. A large number of public services were provided by less efficient state-owned enterprises, resulting in a continuous decline in the number of public service charges [10]. Meanwhile, the government broke the policy of unified revenue and expenditure in the planned economy period after implementing the reform of decentralization and profit-sharing for enterprises. The government no longer implemented the unified revenue policy for the enterprises, thus causing the shrink of local taxes and business [11]. However, there was no change in government expenditure [12]. While guaranteeing the development of local economy, the government had to reduce the burden on enterprises and decrease charges. Thus, in the case of reducing revenue but keeping expenditure, it was a common situation that the revenue could not cover the expenditure [13] and the financial resources were insufficient. In order to develop the local economy and ensure the healthy and orderly market, it is necessary for the government to deeply intervene in the economy [14] and carry out macroeconomic regulation and control. As a result, a large number of departments were required to set. Insufficient financial resources could not meet the operational needs of the department, so it had to ask all departments to find their own financial sources and only give preferential policies to them. Most of the financial resources found by the departments themselves were extra-budgetary revenues, the majority of which were extra-budgetary charges, fines and other incomes. Therefore, the reform of decentralization and profit-sharing have resulted in a decrease in the number of public service charges within the budget, but a large increase in extra-budgetary non-tax revenues.

\subsection{Research on the Influencing Mechanism of Public Service Charges on Financial Decentralization}

There are two paths of influencing mechanism of public service charges on financial decentralization. First, the public service charges affect the degree of decentralizing financial power to society by the local governments. To some extent, the public service charge represents the degree of macroeconomic regulation and control by government, so the increase in public service charges means that the government increases economic intervention. Second, the public service charges affect the degree of decentralizing financial power to local governments by the central government. Therefore, the increase in public service charges within the budget will make the central government know the local actual situation better, while the central government's regulation and intervention to the local will also be strengthened.

The increase in public service charges has led to a decrease in the degree of decentralizing financial power to society by the local governments. As we all know that the public service charges are mainly used to intervene in the negative external behaviors of enterprises, converting the negative external costs into charges, thus reducing their negative external effect. Therefore, the number of public service charges can be used as an indicator of the government to measure the regulation of economy and the intervention of enterprises. When the number of public service charges increase in the local, it indicates that the government increases the intervention on local enterprises and the degree of decentralizing financial power decreases; On the contrary, the degree of decentralizing financial power increases.

The increase in public service charges has led to a decrease in the degree of decentralizing financial power to local governments by the central government. However, the central and local governments have different goals. Generally speaking, the central government has the macroeconomic goals, such as healthy and orderly economy, stable regional coordination and fair revenue distribution, etc. The goals of the local government are mainly including paying attention to the urgent needs of local people and the improvement of local economic development. As a result, the different goals have led to differences in their behaviors and preferences. The local government prefers more autonomous off-budget revenue, while the budgetary revenue has a defined purpose of expenditure. The central government can supervise and evaluate how and where the budgetary fund are used. When the number of public service charges within the budget increases, the central government will strengthen macro-control on the local governments and urge them to make greater efforts to achieve macroeconomic goals. Therefore, the degree of decentralizing power to local governments by the central government will decrease when the number of public service charges within the budget increases. In addition, the public service charges can provide the funds needed for public infrastructure construction. The government attracts foreign investments to obtain a large amount of funds and construct the public service infrastructure [15]. When the amount of charges increases to meet the requirement of constructing the public service facilities, the government will reduce the desire to attract foreign investments. At the same time, the local governments will not compete to attract foreign investments, resulting in inefficiency. The lack of competition would allow the government to perform more non-market decisions and more interventions, thereby causing the decrease in the degree of decentralization. 


\section{Empirical Research}

\subsection{Theoretical Framework}

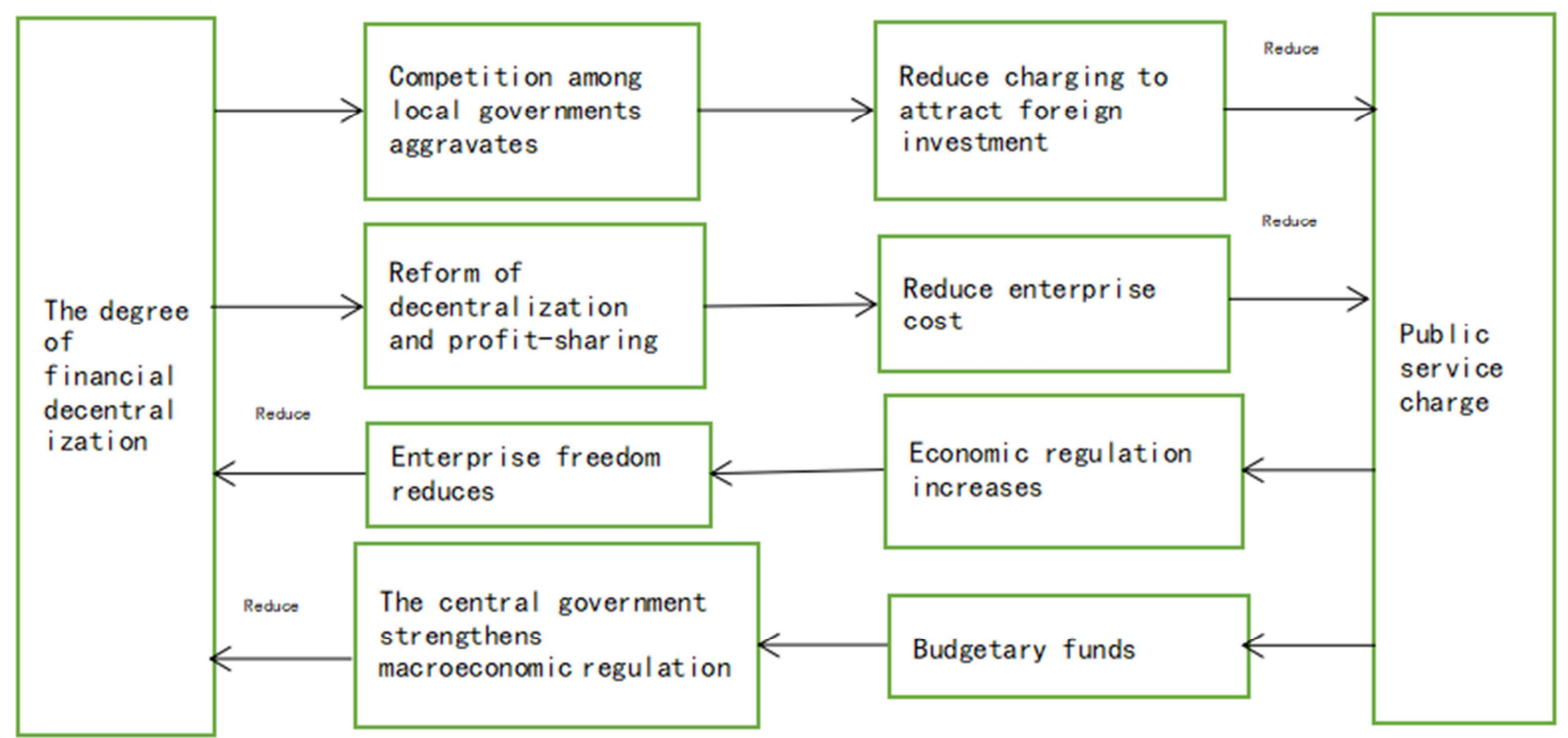

Figure 1. Theoretical framework of two-way interactive effect between financial decentralization and public service charges.

According to Figure 1, we analyze the interactive effect between financial decentralization and public service charges from two directions. The first one is the influence of financial decentralization on public service charges. The number of public service charges decreases with the increase of the degree of financial decentralization. On the one hand, the increase of the degree of decentralizing financial power to local governments by the central government has led to the aggravated competition among local governments. The government has reduced charging to attract foreign investments, resulting in the decrease in public service charges. On the other hand, the increase of the degree of decentralizing financial power to society by the local governments has continuously reduced the burden on enterprises with the reform of "decentralization and profit-sharing". A large part of the burden on enterprise is the charge related to enterprise. Moreover, the promotion of policy has made the government reduce the public service charges. The second direction is that the public service charge increases, while the degree of financial decentralization declines. On the one hand, the increase in public service charges indicates the increased government economic regulation and more intervention in enterprises [16], thus the enterprise freedom reduces. As a result, both the degree of decentralizing financial power to society by the local governments and the degree of financial decentralization decreases. On the other hand, the public service charge measured in this paper is within the general budget. The increase in the public service charge within the budget means the increase in the budget funds. Furthermore, the budget funds should be included in the national treasury, so the central government will know the actual situation of the local better and urge them to make greater efforts to achieve macroeconomic goals. Meanwhile, the central macroeconomic regulation and control is strengthened, thus reducing the decentralization of financial power to local governments by the central government and declining the degree of financial decentralization.

\subsection{Measurement Model and Data}

In this paper, the simultaneous equations were constructed to empirically test the two-way interactive effect between financial decentralization and public service charges. Simultaneous equations can not only effectively solve the endogeneity problem of explanatory variables, but also effectively analyze the influence of other control variables on financial decentralization and public service charges.

\subsubsection{Measurement Model}

$$
\begin{gathered}
\ln \text { ch } \operatorname{arges}_{i t}=\beta_{0}+\beta_{1} f d_{i t}+\beta_{2} \text { gscal }_{i t}+\beta_{3} \ln \text { wage }_{i t}+\beta_{4} \ln \text { garea }_{i t}+D_{q y}+e_{i t} \\
f d_{i t}=\gamma_{0}+\gamma_{1} \ln \text { charges }_{i t}+\gamma_{2} \text { open }_{i t}+\gamma_{3} \text { indus }_{i t}+\gamma_{4} u r b a n_{i t}+\gamma_{5} \ln p g d p_{i t}+D_{q y}+u_{i t}
\end{gathered}
$$

Wherein, equation (1) refers to the public service charg

equation and equation

(2) refers

to the financial 
decentralization equation. The letter "i" stands for each province and the letter " $\mathrm{t}$ " stands for each year. In the public service charge equation, gscal $_{i t}$ stands for the scale of the government of $\mathrm{i}$-th province in $\mathrm{t}$-th year; $\ln$ wage $_{i t}$ stands for the natural logarithm of the average wage of employees in non-private enterprises in i-th province in t-th year; In garea $_{i t}$ stands for the natural logarithm of urban garden green area of i-th province in t-year and $e_{i t}$ is a random item. In the financial pressure equation, open $_{i t}$ stands for the degree of openness of $\mathrm{i}$-th province in $\mathrm{t}$-th year; indus $s_{i t}$ stands for the industrial structure of $\mathrm{i}$-th province in $\mathrm{t}$-th year; $u_{\text {rban }}$ it stands for the urbanization rate of $\mathrm{i}$-th province in t-year; $\ln \mathrm{pgdp} p_{i t}$ stands for the natural logarithm of per capita gdp of i-th province in $\mathrm{t}$-th year and $u_{i t}$ is a random term. $D_{q y}$ is a regional dummy variable, while the eastern region is $\mathrm{qy}=1$ and the central and western regions are $q y=0$. The time effects of individual variables is eliminated with a natural logarithmic mode.

\subsubsection{Data Source and Processing}

In this paper, the panel data is used to conduct an empirical test of 31 provinces in China from 1999 to 2017. The data of Taiwan, Hong Kong Special Administrative Region and Macao Special Administrative Region is not included in this research. The panel data of each province is collected from China Statistical Yearbook, China Finance Yearbook and China Population and Employment Statistics Yearbook.

Table 1. Descriptive statistics.

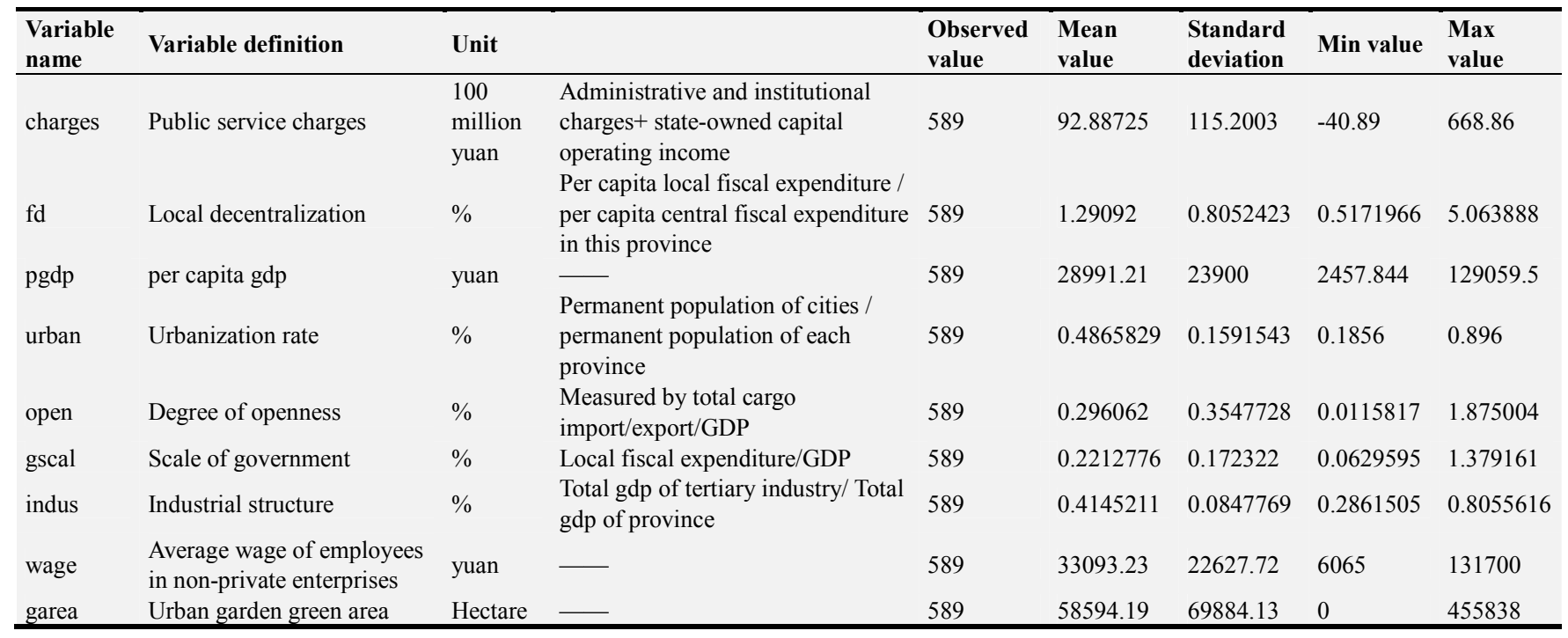

The public service charges variable and financial decentralization variable are the main endogenous variables in this paper [17]. The control variables of public service charge equation mainly include the scale of the government, the average wage of employees in urban non-private units and the urban garden green area. The control variables of financial decentralization equation mainly include degree of openness, industrial structure, urbanization rate and per capita GDP.

\subsection{Analysis of Estimation Method and Empirical Result}

\subsubsection{Estimation Method}

In this paper, the complete information system estimation method was used to construct simultaneous equations. This method can not only effectively interpret the correlation between endogenous variables, but also include the influence of control variables on endogenous variables [18]. The complete information system estimation method mainly adopts the 3 sls method, which is more effective than 2 sls adopted by finite information sheet estimation method and the maximum likelihood estimation adopted by limited information. Moreover, the order conditions and rank conditions that should be satisfied by the simultaneous equations were identified, including five variables not included in the public service charge equation and four variables not included in the financial decentralization equation. The simultaneous equations satisfy the order conditions and rank conditions. The estimation analysis is carried out as follows.

\subsubsection{Analysis of Regression Results}

Table 2. Estimation results.

\begin{tabular}{|c|c|c|c|c|c|c|c|}
\hline \multicolumn{4}{|c|}{ Model 1} & \multicolumn{4}{|c|}{ Model 2} \\
\hline \multicolumn{2}{|c|}{ Public service charge equation } & \multicolumn{2}{|c|}{ Financial decentralization equation } & \multicolumn{2}{|c|}{ Public service charge equation } & \multicolumn{2}{|c|}{ Financial decentralization equation } \\
\hline $\mathrm{fd}$ & $\begin{array}{c}-0.633 * * * \\
{[0.0453]}\end{array}$ & lncharges & $\begin{array}{r}-0.548^{* * *} \\
{[0.0232]}\end{array}$ & $\mathrm{fd}$ & $\begin{array}{c}-0.505 * * * \\
{[0.0540]}\end{array}$ & lncharges & $\begin{array}{r}-0.573 * * * \\
{[0.0225]}\end{array}$ \\
\hline gscal & $-2.981 * * *$ & open & $0.366^{* * *}$ & gscal & $-3.250 * * *$ & open & $0.577 * * *$ \\
\hline
\end{tabular}




\begin{tabular}{|c|c|c|c|c|c|c|c|}
\hline \multicolumn{4}{|c|}{ Model 1} & \multicolumn{4}{|c|}{ Model 2} \\
\hline \multicolumn{2}{|c|}{ Public service charge equation } & \multicolumn{2}{|c|}{ Financial decentralization equation } & \multicolumn{2}{|c|}{ Public service charge equation } & \multicolumn{2}{|c|}{ Financial decentralization equation } \\
\hline & {$[0.1792]$} & & {$[0.0491]$} & & {$[0.2169]$} & & {$[0.0587]$} \\
\hline lnwage & $\begin{array}{r}1.334 * * * \\
{[0.0411]}\end{array}$ & indus & $\begin{array}{r}2.083 * * * \\
{[0.2179]}\end{array}$ & lnwage & $\begin{array}{c}1.388 * * * \\
{[0.0423]}\end{array}$ & indus & $\begin{array}{c}2.055 * * * \\
{[0.2219]}\end{array}$ \\
\hline lngarea & $\begin{array}{r}0.362 * * * \\
{[0.0223]}\end{array}$ & urban & $\begin{array}{r}0.956 * * * \\
{[0.2085]}\end{array}$ & lngarea & $\begin{array}{r}0.384 * * * \\
{[0.0246]}\end{array}$ & urban & $\begin{array}{c}1.176 * * * \\
{[0.2251]}\end{array}$ \\
\hline \multirow[t]{3}{*}{ _cons } & $\begin{array}{c}-12.12 * * * \\
{[0.3931]}\end{array}$ & lnpgdp & $\begin{array}{c}0.532 * * * \\
{[0.0454]}\end{array}$ & cons & $\begin{array}{c}-12.91 * * * \\
{[0.4123]}\end{array}$ & lnpgdp & $\begin{array}{c}0.597 * * * \\
{[0.0466]}\end{array}$ \\
\hline & & _cons & $\begin{array}{c}-3.376^{* * *} \\
{[0.3328]}\end{array}$ & & & _cons & $\begin{array}{c}-3.954 * * * \\
{[0.3393]}\end{array}$ \\
\hline & - & - & - & qy & $\begin{array}{c}-0.282 * * * \\
{[0.0759]}\end{array}$ & qy & $\begin{array}{c}-0.376 * * * \\
{[0.0576]}\end{array}$ \\
\hline $\mathrm{N}$ & 574 & $\mathrm{~N}$ & 574 & $\mathrm{~N}$ & 574 & $\mathrm{~N}$ & 574 \\
\hline AIC & 1084.7 & & & AIC & 1119.1 & & \\
\hline BIC & 1132.6 & & & $\mathrm{BIC}$ & 1175.7 & & \\
\hline
\end{tabular}

Note: The standard deviation is in bracket; $* * *, * *$ and $*$ indicate the significance level of $1 \%, 5 \%$ and $10 \%$, respectively.

Table 2 shows the results of two-way interaction between public service charges and financial decentralization. Among them, model 1 includes regional dummy variable, while model 2 does not include regional dummy variable. According to the results of Model 2, it can be seen that the regional virtual coefficient has a significant effect on public service charges and financial decentralization, but without effect on the control variables. Through screening, Model 2 is selected to analyze the two-way interactive effect between financial decentralization and public service charges.

$i$ The influence of financial decentralization on public service charges. According to the regression results of Model 2, the regression coefficient of financial decentralization on public service charges is -0.505 , passing the significance test of $1 \%$. This indicates that the government's demand for public service charges decreases by $0.505 \%$ when the degree of financial decentralization increases by $1 \%$. That is, the government has a willingness to reduce charges. This is consistent with the analysis above: the increase in the degree of financial decentralization will decrease the public service charges.

ii The influence of public service charges on financial decentralization. According to the regression results of Model 2 , the regression coefficient of public service charges on financial decentralization is -0.573 , passing the significance test of $1 \%$. This means that the degree of financial decentralization decreases by $0.573 \%$ when the public service charge increases by $1 \%$, which is consistent with the analysis above. That is, the increase in public service charges will decrease the degree of financial decentralization.

iii The influence of public service charge control variables on public service charges. The regression result of the scale of government on public service charges is -3.250 , passing the significance test of $1 \%$. This means that the public service charges decrease by $-3.250 \%$ when the scale of government increases by $1 \%$, indicating that the executive powers of the government are expanded with the expansion of its scale. As power expands, the government can gain more monopoly advantages to less rely on the public service charges within the budget. The regression result of average wage of employees in urban non-private enterprises on public service charges is 1.388 , passing the significance test of $1 \%$. This means that the public service charges increase by $1.388 \%$ when the average wage of employees in urban non-private enterprises increases by $1 \%$. The operation of state-owned enterprises and collective enterprises is largely burdened by public service charges, so the public service charges will be increased with the increase of the wages of employees in the state-owned enterprises. The regression result of urban garden green area on public service charges is 0.384 , passing the significance test of $1 \%$. This means that the public service charges increase by $0.384 \%$ when the urban garden green area increases by $1 \%$, indicating that a large part of the expenditure gap of expanding the urban garden green area should be made up by government public service charges.

iv The influence of financial decentralization control variables on financial decentralization. The regression result of openness degree on financial decentralization is 0.577 , passing the significance test of $1 \%$. This means that the financial decentralization increases by $0.577 \%$ when the degree of openness increases by $1 \%$. The government's ability to regulate and control the economy is weakened with the increase in the degree of openness, while it is more likely to cooperate social organizations to develop economy. The regression result of industrial structure on financial decentralization is 2.055 , passing the significance test of $1 \%$. This means that the financial decentralization increases by $2.055 \%$ when the industrial structure increases by $1 \%$, indicating that the government will decentralize more fiscal power to society with the increase in the proportion of tertiary industry. The regression result of the degree of urbanization on financial decentralization is 1.176 , passing the significance test of $1 \%$. This means that the degree of financial decentralization increases by $1.176 \%$ when the degree of urbanization increases by $1 \%$. The level of urbanization is an important indicator of the level of economic development. With the improvement of economic development, the government is more willing to cooperate with the social organizations. The regression result of per capita GDP on financial decentralization is 0.579 , passing the significance test of $1 \%$. This means that the degree of financial decentralization increases by $0.579 \%$ when per capita GDP increases by $1 \%$, indicating that the public demands for public service increase with the improvement of people's living 
standards. Public services provided by the government alone can no longer meet the needs of the society, so the government will decentralize more fiscal power to the society.

\section{Conclusion and Suggestions}

\subsection{Conclusion}

In this paper, the empirical test was carried out for the interactive effect between financial decentralization and public service charges through simultaneous equations. The research results show that there is a negative correlation between financial decentralization and public service charges when financial decentralization affects public service charges. In contrast, there is a positive correlation between public service charges and financial decentralization when public service charges affect financial decentralization. According to the influence analysis on control variables, there is a negative correlation between the scale of government and public service charges. There is a positive correlation between the average wage of employees in urban non-private units, urban garden green area and public service charges. There is a positive correlation between the degree of openness, industrial structure, urbanization, per capita GDP and financial decentralization.

\subsection{Suggestions}

It is necessary to fully consider the two-way interactive effect between public service charges and financial decentralization when promoting the reform of tax and charges reduction and the financial decentralization system reform.

It should pay attention to financial decentralization reform and the decentralization of local government power when carrying out reform of tax and charges reduction. The local government better knows the actual situation in its respective jurisdictions and can perform targeted charges reduction according to the local economic development, thus avoiding drastic fluctuations in the economy. When reducing charges, the government can conduct inquiries and research on local enterprises, and strengthen cooperation with enterprises and social groups, so that the charge reduction can truly benefit the enterprises. In addition, the central government should strengthen the supervision of the local government's implementation process of reducing charges to prevent the occurrence of disguised charges.

The degree of financial decentralization can be increased by reducing the budgetary charges as a breakthrough when promoting the financial decentralization system reform. The off-budgetary charges can be converted into budgetary ones, and then the budgetary charges are reduced to lighten the burden on enterprise. If the charges are included into the budget, it is possible to eliminate the phenomenon of irregular charges and reduce the government's excessive intervention in economy, which is conducive to decentralizing power to society by the government and promoting the continuous improvement of financial decentralization system.

\section{References}

[1] Ma Hongfan. Administrative "zero charge" related to provincial enterprises should be carried out carefully $[\mathrm{J}]$. China Finance, 2017 (19): 45-47.

[2] Jia Bo. Transfer of Non-tax Revenue \& State Governance [J]. Tax Research, 2019 (06): 110-114.

[3] Li Yonghui \& Lin Sen. Research on Non-tax Revenue and Governance of Government [J]. Journal of Jishou University (Social Science Edition), 2018, 39 (01): 56-63.

[4] Wang Jiajie, Tong Jinzhi and Li Xing. Tax Competition, Fiscal Expenditure Pressure and Local Non-tax Revenue Growth [J]. Finance \& Trade Economics, 2014 (05): 27-38.

[5] Tong Jinzhi, Li Xing and Wang Jiajie. Fiscal Decentralization, Multi-level Government Competition and Local Government Non-tax Revenue -- Based on Estimation of Provincial Spatial Dynamic Panel Model [J]. Journal of Social Sciences, Jilin University, 2013, 53 (06): 33-42.

[6] Wang Zhigang \& Gong Liutang. Fiscal Decentralization and Local Government Non-tax Revenue: Based on Provincial Financial Data [J]. World Economic Papers, 2009 (05): 17-38.

[7] Zhu Wenying, Zhang Hao and Wang Xiaoli. Analysis on Internalization Strategy of Logistics External Cost [J]. Business Times, 2012 (24): 37-38.

[8] Lv Bingyang \& Guo Qingwang. The Source of Rapid Tax Growth in China: Interpretation under the Framework of Tax Capability and Taxation Effort [J]. Social Sciences in China, 2011 (02): 76-90+221-222.

[9] Keen. M., C. Kotsogiannis. Does Federalism Lead to Excessively High Taxes? [J]. American Economic Review, No. 9, 2002.

[10] Long Xiaoning \& Zhu Yanli et al. Empirical Analysis of Tax Competition among County Governments in China Based on Spatial Econometric Model [J]. Economic Research, 2014 (8).

[11] Meng Qingyong. Research on Financial Charging System in China [D]. Jilin University, 2005.

[12] Sun Wenji. Analysis of the Status Quo and Reasons of Charges in China [J]. Journal of Suzhou University, 1999 (02): 33-36.

[13] Fan Ziying. The merger of state and local taxes will have a profound impact on local economy and government action [N]. China Economic Times, 2018-05-31 (005).

[14] Lv Wei \& Gao Shuaixiong. Housing Price Fluctuations, Land Finance and China's macroeconomics [J]. Comparison of Economic \& Social Systems, 2016 (4).

[15] Li Yihua. Research on Problem of Government Non-tax Revenue and Strengthening Budget Management [J]. Economic Research Reference, 2018 (28): 3-19.

[16] Shu Hongtao. Contract Management of PPP Toll Road by Using the Cooperation between Government and Social Capital [J]. China Market, 2018 (26): 102-10.

[17] $\mathrm{Wu}$ Jingzhou. Research on the Governance of Institutional Transaction Cost [J]. Price of Commodities in China, 2018 (03): 3-7. 
[18] Xu Xiuchuan. Empirical Research on Interaction between Urbanization, Industrialization and Urban-Rural Income Gap [J]. Agricultural Economic Issues, 2008 (12). 